\title{
A PERCEPÇÃO SENSORIAL E O USO DAS MÃOS: CONSIDERAÇÕES RELEVANTES AO PROJETO DE INSTRUMENTOS MANUAIS
}

\author{
Luciana Ponce da Motta Keller \\ Universidade Federal do Rio de Janeiro \\ keller.luciana@gmail.com \\ Ligia Maria Sampaio de Medeiros \\ PPDESDI-UERJ \\ ligia@esdi.uerj.br
}

Resumo: Este artigo disserta sobre as potencialidades do estudo das mãos humanas no projeto de instrumentos manuais, artefatos destinados à interação com as mãos e que, por meio dela, atuam como extensões do corpo humano. Entende-se que a produção acadêmica brasileira em design ainda é carente nesse tema, que muito tem a contribuir ao design de produto como um todo, especialmente no tange a apropriação da percepção sensorial para fins projetuais. Nesse sentido, este artigo busca enriquecer esta produção, fornecendo subsídios teóricos traçados por autores externos ao campo do design. Argumenta-se a importância, para o designer, de compreender as mãos como entidades indivisíveis do restante do corpo, assim como a percepção sensorial tátil. São abordadas conceituações relativas ao uso das mãos e a consciência corporal, como "mão inteligente", "toque ativo" e "toque localizado, perpassando pela indivisibilidade do sistema "mãos-olhos-cérebro".

Palavras-chave: design de produto, mãos, ferramenta, instrumento manual.

Abstract: This paper discusses the potential of the human hands study applied to hand tools design. Such artefacts are understood here as those intended to interact with the human hands, acting as extensions of the human body. The Brazilian academic production in design is still lacking this kind of discussion, which has much to contribute to product design as a whole, especially about the appropriation of sensory perception for projective purposes. This article seeks to enrich this academic production, providing ideas from authors external to the design field as theoretical basis. It is argued about the importance of the designer understanding of the human hands as indivisible entities from the whole body, as well as from the tactile sensory perception. This paper also brings the discussion of concepts related to the use of the hands and the body awareness, such as the "intelligent hand", the "active touch" and the "touch located, along with the idea of indivisibility of the system" hand-eye-brain".

Keywords: product design, hands, tool, hand instrument. 


\section{INTRODUÇÃO}

Apesar da infinidade de artefatos destinados ao uso pelas mãos, ou mesmo das incontáveis posturas que são capazes de assumir, pouco se discute no campo do design sobre as vantagens e desafios relativos ao projeto de instrumentos manuais. Ainda são poucos os subsídios teóricos aplicáveis ao projeto e configuração desses produtos quando se precisa levar em conta mais do que as dimensões corporais e a mensuração da capacidade musculoesquelética de realizar esforços físicos.

A pesquisa bibliográfica em língua portuguesa sobre o projeto de ferramentas, instrumentos, pegas e manejos de cabos, por exemplo, concentra-se na área da Ergonomia, como se o estudo das mãos se limitasse a evitar constrangimentos ergonômicos. Essa perspectiva, apesar de válida, não faz jus à riqueza de sensibilidades, capacidades e competências das mãos, afinal, elas constituem nosso principal meio de interação com a maioria dos objetos que nos cercam.

Nesse sentido, este artigo visa fomentar tal discussão, fornecendo algumas considerações iniciais para o designer que deseje se aprofundar no estudo dos instrumentos manuais. Esta categoria é entendida aqui como a daqueles artefatos que, para serem utilizados, são tocados ou operados pelas mãos humanas com o propósito de se executar determinada tarefa.

O conceito de tarefa empregado neste artigo é semelhante ao adotado pela Ergonomia, no que se refere à análise da tarefa. Moraes e Mont'Alvão (2012, p.148) exemplificam esse conceito ao ressaltarem a diferença nele contida entre tarefa e atividade: "a tarefa é o objetivo a atingir, o resultado a obter.[...] Para realizar a tarefa, atribuem-se os meios.[...] Para realizar a tarefa com os meios disponíveis e nas condições definidas, o trabalhador desenvolve atividades". Sob esta conceituação, entende-se o instrumento manual como um meio utilizado por uma pessoa (o usuário ou o trabalhador) para, através do uso conjunto entre o objeto e mão, atingir um objetivo, a tarefa, através de ações motoras e mentais, as atividades.

Dentro dessa conceituação, o Instrumento manual é, portanto, um tipo específico de ferramenta que age como extensão do corpo, amplificando ou modificando as capacidades naturais das mãos para a tarefa. Ferramentas e instrumentos pertencem, então, a uma categoria maior: os artefatos. Adereços, objetos decorativos, vestimentas, são artefatos, no entanto, não são entendidos conforme a designação aqui adotada, ferramentas nem instrumentos manuais apesar de serem tocados pelas mãos e sua superfície poder ser apreciada pelo do tato.

Outro fator essencial no projeto do instrumento, porém frequentemente menosprezado, é o papel da percepção sensorial do usuário. As mãos estão entre as partes mais sensíveis do corpo. Seu contato com as superfícies do objeto envia, através do sentido do tato, informações sensoriais ao centro de processamento do cérebro, permitindo detectar, avaliar e apreciar não apenas a textura, mas também o volume, 0 peso, a elasticidade, a consistência, a resistência, a aspereza e a suavidade, características às quais pouca relevância é atribuída na literatura de consulta habitual de estudantes de design. Sendo assim, as considerações a seguir visam complementar as informações acerca desse assunto presentes no campo do design. 


\section{O USO DAS MÃOS E OS INSTRUMENTOS MANUAIS}

Quando se toma um objeto em mãos, uma infinidade de processos cognitivos, motores e emocionais ocorrem instantaneamente, em especial quando esse é manuseado com a finalidade de se realizar algo que as mãos não são capazes de fazer sozinhas. Do mais delicado dos procedimentos cirúrgicos até a mais trivial das ações cotidianas, é necessária uma fantástica integração entre uma ampla gama de segmentações do corpo, atingida através de um longo processo de refinamento evolutivo.

Todas as ações que de algum modo envolvem as mãos, são primeiramente ações do corpo, que através delas se expressa, interage e modifica o mundo. Mesmo sem perceber, "falamos" com as mãos, gesticulando para complementar nosso discurso ou para expressar ideias que visualmente transcendem as palavras. Tanto a ilustração, a escrita, ou o desenho elaborados pelas mãos auxiliam o raciocínio, influenciando o domínio e a reflexão sobre determinado assunto.

Nesse sentido, é necessário primeiramente entender que o corpo é "um com a mente", e não uma entidade independente, que apenas atende a comandos. Quando se estende a mão em direção a um objeto, automaticamente pressupomos diversas informações sensoriais provindas de outros sentidos para além do tato. Mesmo não sendo capazes de "saber em números" quanto pesa uma agulha apenas olhando para ela, somos capazes de "saber com o corpo" exatamente quanta força é necessária para levantá-la, qual postura os dedos devem assumir e quais movimentos devem ser feitos em conjunto com as demais partes do corpo para passar por ela a linha.

Além de antecipar informações sensoriais somos capazes organizar precisamente, em processos simultâneos e inconscientes, inúmeros elementos do corpo e da mente. A perfeição desta integração se dá de tal modo que seus limites se dissolvem, tornando impossível dissocia-los com clareza, uma vez que as partes do corpo e os sentidos nunca atuam sozinhos de fato. Detemos a interessante (e essencial) capacidade de, ao manusear um objeto, estender a ele todas essas articulações, utilizando-o com se fizesse parte integrante do conjunto maior que é o ser que a empunha.

Tudo isso é de uma perfeição impressionante e exclusivamente humana, sendo esse justamente o fato que impede que tais mecanismos sejam facilmente postos em palavras. Por serem tão internalizados, sua observação se torna um desafio particular ao designer que se proponha a projetar instrumentos manuais. Sendo assim, para entender a sensação transmitida por um objeto, não basta que alguém o descreva, é preciso senti-lo. O simples ato de segurar um objeto em mãos é por um lado natural e intrínseco (não precisamos que nos expliquem como segurar um bastão, uma bola ou uma agulha, embora exijam posturas de agarrar e mecânicas de movimento diferentes); por outro, o modo de segurar é uma construção desenvolvida ao longo da vida, juntamente com as significações atribuídas ao objeto e ao ato de manipula-lo.

Desse modo, é possível entender as mãos como um elo, que une o instrumento, a tarefa e aquele que a empunha. Como defende Pallasmaa $(2013$, p.86) "a intenção, a percepção e o trabalho das mãos não existem como entidades separadas", mas ao contrário, esses três elementos compõem um sistema complexo e bem coordenado, que permite ao ser humano, através das mãos, uma compreensão singular do mundo. 
Simultaneamente, os instrumentos manuais podem ser entendidos como uma solução materializada da necessidade de se complementar determinada tarefa, estendendo as capacidades naturais das mãos em sua realização. O resultado dessa materialização é um objeto configurado a partir das concepções socioculturais acerca da tarefa a qual esse se destina, uma vez que esta tarefa está necessariamente imersa em um contexto. Contudo, isso não significa que duas ferramentas concebidas para realizar uma mesma tarefa (ou seja, com um mesmo propósito), produzirão um mesmo resultado. Como afirma de modo provocativo Pallasmaa (2013):

[...] as ferramentas não são inocentes: elas expandem nossas faculdades e guiam nossos atos e pensamentos de maneiras específicas. Afirmar que, para fins de desenho e projeto de arquitetura, o carvão, o lápis, a caneta nanquim e o computador são iguais e que podem ser trocados indistintamente é não entender absolutamente a essência da união entre mãos, as ferramentas e o cérebro. (p.52)

Desse modo, o autor identifica uma intenção nas ferramentas, vinculada diretamente a nossas capacidades cognitivas, uma vez que impactam o modo como realizamos a tarefa, bem como o modo como entendemos que a ferramenta deve ser usada. No entanto, essa intenção também diz respeito à percepção simbólica e emocional do individuo frente ao uso do objeto, pois a percepção em relação à ferramenta vai para além da cognição, perpassando a relação pessoal que se tem com a ferramenta, a prática, as experiências vividas e seus significados. Em relação à tarefa de desenhar, Pallasmaa (2013, p.98) acrescenta:

Não há dúvidas de que o computador facilita a maior parte dos aspectos da prática da arquitetura de maneira decisiva e, além de ser uma ferramenta de desenho rápido e preciso [...]. Os problemas do projeto totalmente gerado por computador são evidentes particularmente nas fases mais sensíveis e nas etapas mais vulneráveis do processo de projeto, quando a essência da arquitetura de uma edificação está sendo concebida e determinada. A mão com um pedaço de carvão, um lápis ou uma caneta cria uma conexão tátil direta entre o objeto, sua representação e a mente do projetista; o croqui, o desenho ou a maquete feito a mão é moldado na mesma espécie de materialidade física que o objeto que está sendo projetado e que o próprio arquiteto corporifica, enquanto as operações e o imaginário gerados por computador ocorrem em um mundo matemático, imaterial e abstrato.

Ainda que objetos diferentes possam ser destinados a uma mesma tarefa, como o carvão, o lápis, a caneta e o computador podem ser utilizados para desenhar, tanto a sensação de utiliza-los quanto seus resultados serão diferentes. Consequentemente, uma solução material universal para uma tarefa é uma abstração equivocada, pois a intenção de complementar a tarefa é apenas parte do que compõe a ferramenta. Para o autor, "o desempenho e a aparência de uma ferramenta inevitavelmente reflete a postura específica de sua cultura frente ao trabalho e ao valor social conferido a este" (Pallasmaa, 2013 p. 51).

Talheres, por exemplo, são utilizados para complementar a tarefa de "comer". Apesar de sermos capazes de comer utilizando apenas as mãos, a refeição possui uma forte 
importância social, o que necessariamente se reflete na configuração física destes utensílios (ou em sua ausência). Os talheres auxiliam a mão a levar o alimento até a boca, e refletem, em sua forma, matérias e acabamento, as concepções de determinada cultura sobre os modos à mesa, os diferentes tipos de alimento, os rituais de consumo e produção da comida, etc. Ou seja, refletem os contextos, os valores e as práticas que atribuem ao ato de comer a sua dimensão sociocultural, construída ao longo de gerações.

A colher apresentada na figura 1, abaixo, exemplifica essa ideia. Originária de um povo nômade do noroeste da China, ela se distingue pelos aros em seu corpo. $\mathrm{O}$ aro na parte superior serviria para amarrar a colher junto ao corpo ou outros pertences, 0 que não ocorria com as colheres chinesas dos povos sedentários de seu tempo. Outra diferença marcante se refere aos pingentes de metal (originalmente, os outros dois aros inferiores também possuiriam pingentes), que produziriam um barulho característico ao se manusear a colher, como um chocalho, o que faz com que a colher se assemelhe mais com os artefatos produzidos pelos povos vizinhos a China à época. Segundo Bunker (2002, p.178): “Guizos que faziam barulho quando os objetos a que estavam presos eram movidos eram proeminentes em culturas nas quais o xamanismo desempenhava um papel importante", diferentemente dos sinos musicais chineses.

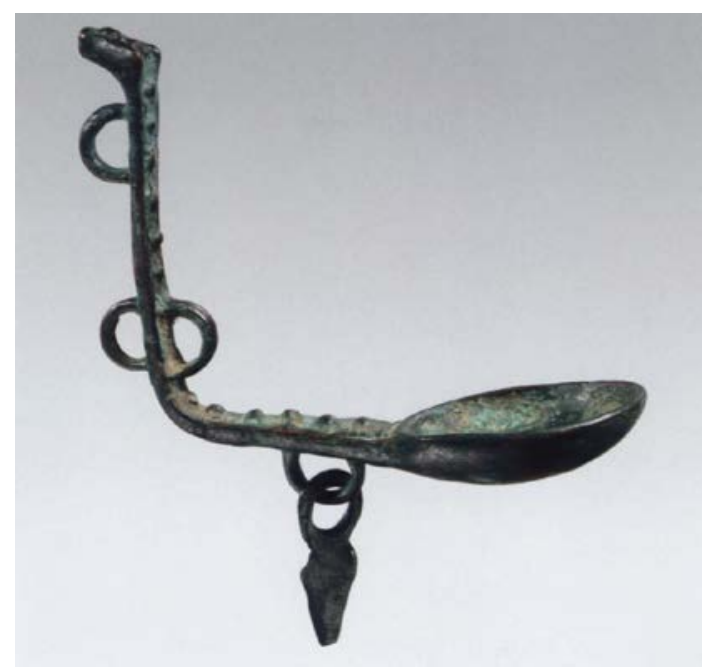

Figura 1 - Colher de bronze do noroeste chinês, de aproximadamente $15 \mathrm{~cm}$, datada entre os séculos XIII e XI A.C. Fonte: Bunker (2002, p.192)

Esse rápido exemplo ilustra como mesmo um artefato cotidiano tão básico quanto a colher, é capaz de expressar traços culturais tão marcantes quanto a identidade cultural do povo que a concebeu e a utiliza. Nesse sentido, Pallasmaa (2013) explora a ideia de que cada ferramenta carrega em si características necessárias ao homem para executar seu trabalho ou atividade cotidiana, criando uma relação de significação entre sua configuração física e o indivíduo que o utiliza. Para o autor, esta relação se faz ainda mais especial quando o usuário é aquele que produz sua própria ferramenta:

As ferramentas são extensões e especializações das mãos que alteram seus poderes e capacidades naturais. Quando um machado ou uma faca está sendo utilizada, o usuário competente não considera suas mãos e a ferramenta como duas entidades separadas; a ferramenta se transformou em parte de suas mãos, e ambas se 
tornaram uma espécie inteiramente nova de órgão, uma mão "mãoferramenta". (PALLASMAA, 2013 p.49-50)

Classificando-as como "extensões das mãos", tem-se ainda uma definição vaga do que vem a ser uma ferramenta, uma vez que, como exemplifica o próprio autor: "a sala de cirurgia inteira, com seus inúmeros instrumentos, máquinas e assistentes técnicos, é uma extensão das mãos do cirurgião" (IDEM, p.53). Sob essa perspectiva, uma infinidade de artefatos e ambientes pode ser classificada como "ferramenta". Contudo, fica evidente a relevância da conexão direta estabelecida entre as ferramentas e as mãos.

As mãos humanas evoluíram não apenas para se adaptar às ferramentas, mas junto com elas. O design desses objetos desenvolveu-se juntamente com a própria capacidade humana de concebê-los a partir de suas necessidades e de produzi-los de acordo com suas limitações físicas, materiais e cognitivas. Do mesmo modo, as mãos humanas apresentam uma relação direta com as ferramentas. Segundo Pinker (1998) "A produção e o uso de utensílios é a aplicação de conhecimentos sobre causa e efeito entre objetos, visando atingir objetivos". Para o autor:

Os artefatos acompanham a condição humana. Fabricamos utensílios e, no decorrer de nossa evolução, nossos utensílios nos moldaram. [...] O que é um artefato? É um objeto apropriado para atingir alguma finalidade que a pessoa tenciona que seja usado para atingir essa finalidade. A mistura de mecânica e psicologia faz dos artefatos uma categoria estranha. Os artefatos não podem ser definidos segundo sua forma ou constituição, apenas pelo que podem fazer e pelo que alguém, em algum lugar, deseja que eles façam. (p.347-8)

Tendo os instrumentos manuais como uma categoria particular de artefatos, evidencia-se a ligação entre o fazer humano, o uso de ferramentas, o desenvolvimento cognitivo e a evolução das mãos. Esses conceitos constituem um meio através do qual é possível obter uma perspectiva macro da percepção, tanto no sentido da percepção geral que se pode ter sobre um objeto, como especificamente da percepção sensorial. Abordando as questões relativas ao fazer humano, somos direcionados ao fazer manual e, posteriormente, ao entendimento de como um instrumento manual é sensorialmente percebido e concebido.

\section{AS MÃOS INTELIGENTES}

A fim de se privilegiar as sensações experimentadas pelas mãos, propõe-se aqui a exploração de três conceitos centrais ao projeto de instrumentos manuais: a Preensão, o Toque Ativo e o Toque Localizado. Antes de detalha-los, no entanto, é necessário acrescentar que todos partilham da ideia de que o corpo humano (especialmente a mão) possui uma "inteligência própria", uma forma de conhecimento e compreensão do mundo construída por meio das experiências físicas vivenciadas.

Partindo desta compreensão, Sennett (2013) e Pallasmaa (2013) exploram o conceito de mão inteligente, que expressa a íntima relação entre o trabalho das mãos e o do cérebro. Desta ligação resultam algumas das mais importantes conquistas evolutivas para a humanidade, como o desenvolvimento de uma alta capacidade cognitiva, 
compreensão tridimensional do mundo, a impressionante coordenação motora e o intrincado desenvolvimento da linguagem.

Por meio do toque e do tato, as mãos são primordiais para a construção da experiência tátil-visual do ser humano, pois formam concepções materiais através da atuação dos sentidos. As crianças, por exemplo, sentem curiosidade natural em tocar coisas novas. De certo modo, elas "veem" com as mãos, mas, com o tempo, os adultos as ensinam a não fazê-lo. Contudo, esse processo também acontece sem que tenhamos ciência. "Quando um amigo retira um objeto interessante do bolso e se exclama 'que interessante, deixe-me vê-lo', o que, frequentemente, se quer dizer na realidade é 'deixe-me senti-lo'” (NAPIER, 1993).

Todas essas características complexificam as mãos de tal modo que é difícil identificar os limites de sua atuação quando usadas para interagir com o mundo, para comunicar emoções, para auxiliar o raciocínio abstrato, dentre tantas outras funções práticas. Através do tato, a mão oferece vantagens sobre a visão, por ser capaz de "ver através de quinas" e "ver no escuro", além de permitir que as atividades motoras e sensoriais funcionem a alguma distância do corpo (NAPIER, 1993).

As palavras toque e o tato, que têm como principal agente a mão, frequentemente remetem de imediato à ideia de "percepção de texturas". Todavia, através do tato somos capazes de depreender mais do que simplesmente a textura dos objetos. Ao empunhar uma ferramenta, sentimos não só sua configuração física ou a textura do material do cabo, mas seu peso, sua proporcionalidade, a sensação térmica proporcionada por ela, conforto, firmeza. Ao segurar algo também sentimos através das mãos empatia, nos identificamos ou estranhamos, sendo capazes de depreender intenções presentes nos objetos, indos além da mera mensuração de dados.

Essa capacidade empática das mãos expressa o quão indivisível é a percepção do instrumento pelos sentidos (não apenas do tato) na realização da tarefa. Juntamente ela, uma das habilidades que melhor representa o conceito de mão inteligente é o modo como nos apropriarmos de objetos, utilizando-os como extensões não só do próprio corpo, mas também da mente. Pallasmaa (2013) resume essa ideia ao afirmar que "as mãos tomam a dimensão física e material do pensamento e as tornam em uma imagem concreta" (p.17). Ou seja, ao se sentir o mundo com as mãos, segurar, manipular e tocar, não apenas "absorvemos informações", mas nos apropriamos das coisas, conferindo a elas materialidade e significado.

Mesmo tarefas simples exigem uma coordenação precisa em sua execução. Essa coordenação acontece entre três elementos do corpo que evoluíram para trabalhar como um só: as mãos, os olhos e o cérebro. A sincronia desse conjunto mãos-olhoscérebro permite que, ao segurar um objeto, por exemplo, as informações armazenadas no cérebro sobre $o$ ato de segura-lo confere sentido a uma fotografia bidimensional do mesmo. "A curvatura da mão e a percepção, [...] ajudam o cérebro a pensar em três dimensões ao ver em relevo, no papel, um objeto chato" (SENNETT, 2013 p.147). Sendo assim, a tridimensionalidade, juntamente com a coordenação mão-olho-cérebro e a articulação harmônica entre os sentidos são também "inteligências" da mão, compondo parte da percepção somatossensorial.

Pallasmaa (2013) relaciona a coordenação mãos-olhos-cérebro diretamente à construção da materialidade necessária ao raciocínio projetual. Ao realizar uma tarefa 
repetidas vezes, independentemente de sua complexidade, confere-se a ela sentido e familiaridade. Assim, o fazer é naturalizado de tal modo que se cria um senso de identidade sobre ele. Segundo o autor:

A união entre os olhos, as mãos e a mente cria uma imagem que não é apenas um registro visual do objeto: ela é o objeto. [...] No momento em que o jogador de um esporte com bola golpeia ou pega a bola, o complexo entre olhos, mãos e mente já realizou cálculos instantâneos e inconscientes sobre as posições espaciais relativas às velocidades e os movimentos, bem como já fez uma série de planejamentos estratégicos. Essa cansativa tarefa de fundir as dimensões do tempo [...] em uma ação que leva uma fração de segundo, é apenas possível graças a pratica assídua que culminou na corporificação da tarefa, tornando-a um ingrediente do senso de identidade pessoal do atleta, em vez de fazer com que ele enfrente a situação como uma tarefa externa e desvinculada de seu corpo. (PALLASMAA, 2013 p. 84-5)

A dificuldade em compreender o processo de corporificação da tarefa, nos termos de Pallasmaa (2013), reside em sua internalização. Por ser tão natural e fluido que pode ser o desafio em particular para o designer pô-lo em palavras, parecendo ao mesmo tempo demasiadamente óbvio e trabalhoso de explicar. No entanto, esse processo de apropriação de instrumentos pela mão inteligente (enquanto uma extensão do próprio ser) é essencial para compreensão das questões que conferirão ao designer os caminhos projetuais não óbvios.

\section{A PREENSÃO}

O termo preensão, deriva da pala latim prehendere, que significa "agarrar", designando a capacidade genérica de objetos. Embora diversos membros de animais possuam a capacidade preensiva (como a cauda dos macacos, a tromba dos elefantes, os tentáculos dos polvos, etc.) nenhum demonstra os mesmos níveis de destreza, precisão, agilidade ou versatilidade das mãos humanas (WILSON, 2010). Wilson (2010) atribui ao pesquisador John Napier as primeiras terminologias utilizadas para caracterizar a preensibilidade das mãos humanas. Segundo o autor, em um artigo científico em 1956, Napier introduziu os termos "power grip" (manuseio de força) e "precision grip" (manuseio de precisão) como a intenção de simplificar o método de avaliação clínica da funcionalidade das mãos e dos efeitos de lesões. Inicialmente, sua intenção era separar movimentos "preensíveis", aqueles nos quais um objeto é empunhado parcialmente ou completamente pela mão (escovar os cabelos ou os dentes); dos "não-preensíveis", aqueles nos quais o objeto é manipulado pela mão e pelos dedos, mas não agarrado (digitar ou tocar piano).

Para o autor, a contribuição-chave de Napier em relação à manipulação e o controle das mãos foi o entendimento de que o fator determinante está na tarefa, e não na configuração física do objeto. Segundo Wilson (2010):

Napier entendeu que para os humanos não é a ferramenta, mas a tarefa que determina o manuseio. Independentemente do formato do objeto sendo segurado, seu uso pretendido define automaticamente a intensidade esperada para o controle de ambos a força e a amplitude (isso é, potência e precisão) do movimento. A 
postura de agarrar não é aleatória: na verdade, é um registro altamente preciso de antecipações neurológicas para os requerimentos biomecânicos da tarefa.

Nesse mesmo sentido, Pinker (1998) exemplifica o incrível controle cerebral do homem sobre suas mãos, a partir da simples ação de erguer um pacote de leite: "Se não apertar o suficiente, você o deixará cair; se apertar demais, o esmagará; e balançando de leve você pode até mesmo usar os movimentos sob as pontas dos dedos como um medidor de nível para saber quanto leite há dentro!". Se, por um lado, esse é um processo fundamental para a interação do homem com o mundo, por outro, é tão inconsciente e espontâneo que raramente presta-se a devida atenção a ele.

Quando se segura algo, a força aplicada e a postura assumida pelas mãos inconscientemente ajustam-se perfeitamente ao objeto. Antes mesmo de toca-lo, o cérebro já "sabe" (ou supõe) diversas informações sobre o objeto, como peso, textura, temperatura, principalmente por meio da visão, mas também por meio de toda uma vida de exploração tátil. Do mesmo modo que os "cálculos instantâneos e inconscientes" citados por Pallasmaa (2013), essenciais para a coordenação motora como um todo, a capacidade das mãos de "saber" como segurar, tocar e manusear é também um processo imediato, no qual não se tem ciência sobre.

Sennett (2013) atribui à preensão a qualidade de antecipar e "agir na frente" dos dados sensoriais, o que, como já citado, ocorre por meio das vias extrapiramidais. Por meio da preensão, a coordenação mão-olho-cérebro é capaz de antecipar as informações provenientes da exploração multissensorial, devido a sua construção conjunta e sincronizada. Isso torna possível, por exemplo, que antes mesmo de pegar um copo com água, apenas ao olhá-lo, a "mão saiba" seu peso, quanto de força deve aplicar para levantá-lo e de que modo.

Essa capacidade, por ser integrada, se estende igualmente a linguagem e ao entendimento de conceitos abstratos. A preensão segundo o autor, "confere determinada configuração ao entendimento mental, assim como a ação física: não esperamos para pensar até que todas as informações estejam à mão, antecipamos o significado" (SENNETT, 2013 p.174). Sendo assim, a preensão atua desde a habilidade de segurar objetos (que apesar de cotidiana, nada tem de simples), até a própria capacidade humana de se apropriar de significados e conceitos, ligando-se diretamente à percepção do mundo e ao raciocínio espacial, visual e abstrato.

Além do papel fundamental desempenhado pela mão para a preensão, suas capacidades motoras superam suas capacidades de percepção sensorial. Segundo Tortora e Derrickson (2010): “A mão possui uma representação maior na área motora do que na área somatossensorial, o que implica maior precisão no controle dos movimentos da mão do que a capacidade refinada em sua sensação" (p.589). Os autores também acrescentam que "os tamanhos relativos dessas regiões na área somatossensorial são proporcionais ao número de receptores sensitivos especializados no interior da parte correspondente do corpo", contudo, é possível expandi-lo ou encolhe-lo, de acordo com os impulsos recebidos em determinada parte do corpo. Um exemplo são as pessoas que aprendem a ler Braille, que desenvolvem um aumento na área cortical somatossensorial da ponta dos dedos. 


\section{TOQUE ATIVO E TOQUE LOCALIZADO}

O conceito de toque ativo foi cunhado pelo neurofisiólogo Sir Charles S. Sherrington, referindo-se à intencionalidade contida no sentido do tato ao guiar os dedos em busca de informações sensoriais. $O$ toque ativo identifica o intuito consciente que guia a mão ao explorar e identificar os objetos no ambiente, podendo ser atingida apenas quando os movimentos das mãos e dos olhos trabalham em harmonia (WILSON, 2010).

Segundo Sennett (2013), a importância desse conceito reside no fato de que, até ser contestado pelo pesquisador, o tato era considerado um sentido passivo. Ao contrário de uma visão agressiva, que pode ser anulada ao fechar os olhos, sensações "invasivas" como a dor de um corte ou de uma queimadura não podem ser igualmente neutralizadas. Por esta razão, os dados sensoriais fornecidos pela visão eram tidos como diferentes dos fornecidos pelo tato, considerados como "descontrolados". A afirmação de Sherrington, então, conferiu ao tato status tanto de proativo quanto de reativo, sendo capaz de estabelecer relações de significação, providenciando ao cérebro informações necessárias tanto à compreensão do mundo, quanto para a realização de movimentos delicados.

Para Wilson (2010), alguns pesquisadores (inclusive Sherrington) consideravam as pontas dos dedos como "máculas somatossensoriais". Sendo assim, a mão traria os objetos para serem manipulados dentro do campo central de visão, permitindo que os movimentos mais delicados dos dedos estejam sobre controle simultâneo dos centros da mácula visual e tátil. Todavia, o tato não se limita a essa restrição, uma vez que envolve diretamente a análise de tamanho e de volume, além de ser crítico para que sejam captadas as propriedades do objeto como dureza, textura, temperatura, peso, dentre outros, o que dificilmente pode ser verificado apenas pela visão.

Sennett (2013) afirma que, em relação à proatividade do tato, a pesquisa de Sherrington ganhou continuidade dando lugar a um novo conceito, o toque localizado, que pressupõe a independência entre a mão e o olho. Segundo Sennett (2013, p.173) "os dedos podem sondar de maneira proativa pelo tato sem intenção consciente, como nos momentos em que buscam determinado ponto específico num objeto para estimular o cérebro a começar a pensar; é o chamado toque "localizado'".

Ao atribuir mais esta competência ao tato, Sennett (2013) reforça a importância das mãos para o processo projetual, bem como a materialidade conferida por elas, uma vez que o tato é responsável por estimular o raciocínio. Nessa perspectiva, o raciocínio ao qual o autor se refere é uma inteligência espacial, tridimensional, material e concreta, sendo auxiliado pela construção conjunta do mundo através dos sentidos.

Ao fazer tais afirmações, o autor vai ao encontro das proposições de Pallasmaa (2013), que defende igualmente a importância do tato e da conexão mão-olho-cérebro, um processo inconsciente, para o trabalho de todos os profissionais que, de algum modo, produzem através das mãos (como o designer). Pallasmaa (2013) atribui importância às capacidades da mão e do tato por fundamentarem a materialidade necessária ao raciocínio projetual. $\mathrm{O}$ sentido do tato, para o autor, carrega em si um processo quase instintivo (ou inato), mas de grande valia para o profissional, pois "media mensagens de convite e rejeição, proximidade ou distância, prazer ou repulsa. É exatamente essa dimensão inconsciente do toque na visão que é desastrosamente negligenciada na arquitetura [...], que são preconceituosas a favor da visão" (PALLASMAA, 2013 p.105). 
Sob esse aspecto, entretanto, Pallasmaa (2013) vai além, caracterizando o tato como uma modalidade sensorial que integra as experiências, memórias e concepções do indivíduo. Para o autor, a apropriação do tato pelo designer e pelo arquiteto também é fundamental, pois o sentido media a relação entre a experiência do usuário e o sentido do profissional. Nessa perspectiva, portanto, a experiência tátil do momento do uso é essencial para a percepção da qualidade para o usuário, uma vez que agencia o contato indireto com o designer. Segundo o autor, "objetos e edifícios agradáveis mediam uma experiência dos processos pelos quais eles foram produzidos; de certo modo eles convidam o observador ou usuário a tocar nas mãos do artista" (p.106).

Toque ativo e toque localizado podem ser diferenciados por dois elementos-chave: a ligação entre o olhar sobre a atividade das mãos e a intencionalidade no uso do tato para a realização da tarefa. No toque ativo descrito por Sherrington, a mão possui a função de trazer intencionalmente os objetos para dentro do campo visual, trabalhando em conjunto com os olhos para exercer determinada tarefa. É através da soma das sensações táteis e visuais que se permite o trabalho delicado de manipulação. Já no toque localizado descrito por Sennett (2013), a mão age independentemente dos olhos, buscando por informações sensoriais sem que haja necessariamente a consciência do que se está procurando, embora ainda exista a intencionalidade do ato ao tatear o objeto ou o ambiente. Quando, por exemplo, coloca-se a mão dentro de uma mochila para procurar as chaves, tateando seu interior (toque localizado), a intenção de achar o objeto existe, mas não a compreensão clara de como a mão foi capaz de fazê-lo. Já quando se coloca o lápis e papel em frente ao corpo para escrever (toque ativo), os objetos são trazidos intencionalmente para dentro do campo visual, mas não se compreende como as sensações de segurar o lápis permitem o desempenho da tarefa.

Ambos os conceitos representam diferentes aspectos dentre os inúmeros que compõem a percepção do indivíduo em relação ao objeto, sendo, portanto, dimensões complementares do trabalho manual, e não excludentes. Mesmo não sendo capaz de executar as duas modalidades de toque simultaneamente, a mão pode alternar entre uma e outra, tendo ambas ao seu dispor. Ao aprender uma nova habilidade, como dirigir, por exemplo, é comum que inicialmente o olhar do individuo acompanhe atentamente a atividade das mãos, para aos poucos internalizar seus movimentos.

Todavia, mesmo não compreendendo o funcionamento do toque ativo e do toque localizado em sua plenitude, esses conceitos são recursos valiosos para o designer interessado pelo trabalho das mãos. Ao criar a consciência de que esses processos ocorrem, o profissional é capaz de, por meio da observação, discernir mais refinadamente como se dá a interação entre as mãos do usuário e do produto. A partir dessa observação, conclusões mais específicas podem ser obtidas sobre o instrumento em questão, pois cada configuração física, assim como cada contexto e cada usuário, resultará em uma percepção específica e uma resposta singular das mãos.

\section{CONSIDERAÇÕES FINAIS}

São múltiplas as considerações necessárias ao designer de produto que deseje projetar instrumentos manuais que considerem as particularidades das mãos humanas. Possivelmente, uma das mais relevantes é o risco de se pressupor que é possível "isolar" a percepção tátil das mãos, como se essa pudesse ser desmembrada do 
restante do corpo e dos outros sentidos. Para entender como as mãos "percebem", primeiramente é necessária uma noção mais geral de como se dá essa percepção. Para isso, se propõe adotar perspectivas mais holísticas, como a de Pallasmaa (2013) em relação à indivisibilidade de tarefas mentais e físicas, que compreende o corpo humano (em especial a mão) como "um com a mente". Portanto, entende-se que é infrutífero para o designer buscar isolar qualquer um dos elementos do sistema mãosolhos-cérebro durante a execução da tarefa. Igualmente, não se pode propor um isolamento desses elementos com a percepção sensorial, ou mesmo considerar as mãos separadas entre si, pois seu trabalho é conjunto e complementar.

Outros conceitos-chave apresentados, como a mão inteligente, o toque ativo e o toque localizado, apesar de não abrangerem todo o potencial de discussão oferecido pelo tema, auxiliam o designer a compor uma compreensão mais rica da relação usuário em ao instrumento manual. Uma vez compreendida a complexidade dessa relação, mais completa é a análise do designer em relação ao papel da mão na percepção somatossensorial, além de seu profundo enraizamento na construção das experiências sensoriais tanto do usuário quanto do designer.

Esses subsídios permitem ao o designer atentar-se em sua observação ao modo como o usuário se apropria do tato e do contato físico para interagir com o objeto, auxiliando-o a identificar as características mais relevantes (ou determinantes) na configuração física de determinado instrumento manual. Por esta mesma razão, o designer também será capaz de melhor se apropriar de suas próprias observações em relação ao instrumento, pois, ao segura-lo e manuseá-lo, estará mais atento ao uso do tato, bem como as sensações físicas influem em sua percepção do objeto.

Sendo assim, devido à riqueza e complexidade do trabalho executado pelas mãos humanas, diversos assuntos abordados deste artigo, merecem aprofundamento em trabalhos futuros, especialmente sob outros recortes. Dentre estes assuntos pode-se citar: a relação entre a construção da linguagem, da cognição e do uso das mãos; a evolução conjunta das mãos e do cérebro; a indivisibilidade da percepção somatossensorial e da percepção através das mãos; a influência da capacidade comunicativa das mãos para a concepção da ferramenta; o amplo repertório de gestos de posturas envolvidos no manuseio; além das diversas contribuições de autores que se dedicaram ao estudo das mãos em diversas áreas do conhecimento.

\section{REFERÊNCIAS}

BUNKER, Emma C. Nomadic art of the eastern eurasian stepps: the Eugene V. Thaw and other New York collections. The Metropolitan Museum of Art: New York, 2002.

MORAES, Anamaria de; MONT'ALVÃO, Claudia. Ergonomia: Conceitos e aplicações. 4. Ed. Rio de Janeiro: 2AB, 2012. 224p.

NAPIER, Jhon. Hands. ed. rev. Rev. Russell H. Tuttle. Princeton: Princeton University Press, 1993. 169p.

PALLASMAA, Juhani. As mãos inteligentes: A sabedoria Existencial e Corporalizada na Arquitetura. Tradução de Alexandre Salvaterra. Porto Alegre: Bookman, 2013. 160p.

PINKER, Steven. Como a Mente Funciona. Tradução de Laura Teixeira Motta. 3. ed. São Paulo: Companhia das letras, 1998. 671p. 
SENNET, Richard. O artífice. Tradução de Clóvis Marques. 4. Ed. Rio de Janeiro: Record, 2013. 360 .

TORTORA, Gerald G; DERRICKSON, Bryan. Princípios de anatomia e fisiologia. Tradução de Alexandre Lins Werneck, 12. Ed. Rev. Rio de Janeiro: Guanabara Koogan, 2013. 1170p.

WILSON, Frank R. The hand: how its use shapes the brain, language, and human culture. ed.rev.Nova York: Vintage Books, 2010. 416p. 